\title{
Screening of Biotechnological Parameters for Fructofuranosidases Production by a Newly Isolated Fungal Strain Using Plackett-Burman Design
}

\author{
Camelia BONCIU NEAGU*, Oana CONSTANTIN, Gabriela BAHRIM \\ Dunarea de Jos University, Food Science and Engineering Faculty, 111 Domneasca Street, \\ 800201, Galati,Romania; cbonciu@ugal.ro ( ${ }^{*}$ corresponding author)
}

\begin{abstract}
Previously some fungal strains with good inulinase potential biosynthesis were screening and the most performing strain is the newly fungal strain, Rhizoctonia spp. coded I-PN4. In this study, the Plackett Burman design was used to identify the effect of process parameters upon fructofuranosidases (inulinase and invertase) production with new selected fungal strain. The agitation rate, yeast extract, buckwheat flour and $\mathrm{K}_{2} \mathrm{HPO}_{4}$ concentration from fermentative medium composition, were determined as the most influential variables that have positive effects on fructofuranosidases biosynthesis. Temperature has a negative effect on both invertase and inulinase biosynthesis yield. In optimal established fermentative conditions, the maximum yields for extracellular inulinase was 6.2198 UI and 4.7664 UI for invertase respectively. The linear model fits well for variable screening and is globally significant, as $\mathrm{R}^{2}$ is $88.36 \%$ for inulinase production and $84.24 \%$ for invertase production respectively.
\end{abstract}

Keywords: biotechnological parameters screening, fungal selected strain, inulinase, Plackett Burman design

\section{Introduction}

Inulin is a reserve carbohydrate consisting of linear chains of $\beta-2,1$-linked $D$-fructofuranose terminated by a glucose residue at the reducing end. It can be found in plants like Jerusalem artichoke, dahlia and chicory and in small amounts in onion and garlic (Chi et al., 2009, 2011). Vegetal sources rich in inulin have received a great interest as they are a renewable, inexpensive and abundant raw material for fructose syrup production, bioethanol obtaining and other chemicals production (like citric acid, ultra high fructose syrup, single cell protein, single cell oil, inulo-oligosaccharides) (Chi et al., 2011; Kango, 2008; Sharma et al, 2006).

Inulinases are hydrolysis enzymes that target on the $\beta-2,1$ linkage of inulin, resulting fructose and glucose as hydrolysis products (Chi et al., 2009). Microorganisms are the best sources for inulinases and invertases. So far, many moulds and yeasts were tested for inulinases production and some of them could produce high inulinase activity. Among them, Kluyveromyces marxianus (Bender et al., 2006; Kalil et al., 2001; Kushi et al., 2000; Mazutti et al., 2007; Singh et al., 2006; Treichel et al., 2009), Pichia guilliermondii (Gong et al., 2007; Yu et al., 2009), Cryptococcus aureus (Sheng et al., 2008), Candida kefyr (Pessoa et al., 1998), some yeast strains isolated from marine microbiota (Gao et al., 2007), Aspergillus ficuum (Chen et al., 2011), Aspergillus niger (Kango, 2008; Kumar et al., 2005), Pseudomonas spp. (Kim et al., 1997), Arthrobacter spp. (Kang et al., 1998), Streptomyces spp. (Sharma et al., 2006) have proven to be good producers of inulinases.
Inulinases are wide used for fructooligosaccharides production, as nutraceutical products which have good functional and nutritional properties.

Many microbial preparations of inulinase present also invertase activity accompanying the inulinase activity (Mazutti et al., 2006; Sharma et al., 2006). Invertase splits the $\beta-(2,1)$ fructoside linkages of sucrose and gained importance in the last years due to its various biotechnological applications in beverage, confectionary, bakery and pharmaceutical industries (Kaur and Sharma, 2005).

The purpose of the present study is to screen for the principal factors that can affect fructofuranosidases (inulinase and invertase) biosynthesis and yield of extracellular enzymes released by a newly isolated fungal strain, using Plackett-Burman design. In the present work, eight variables were studied in 12 experiments and 4 center samples. The carbon source (onion flour, Jerusalem artichoke flour and buckwheat flour in the range 0-6\%), nitrogen source (soy flour, yeast extract, in the range $0-2 \%$ ), salt $\left(\mathrm{K}_{2} \mathrm{HPO}_{4}\right.$, in the range $0-1 \%$ ) and some process parameters (temperature, in the range $20-40^{\circ} \mathrm{C}$ and agitation, in the range 0-200 rpm) were taken into consideration as significant variables.

\section{Materials and methods}

\section{Microorganisms}

Rhizoctonia spp. (coded I-PN4) previously selected as good producer of inulinase was isolated from soil from Jerusalem artichoke tubers (Bonciu et al., 2010). The newly isolated strain has proven the best ability to hydrolyze 
272

inulin from Jerusalem artichoke tubers in comparison with some selected strains from Bioaliment Platform Collection (acronym MIUG), belonging to Aspergillus niger, Aspergillus oryzae and Rhizopus spp. strains (Bonciu et al., 2010). Rhizoctonia spp. strain was identified based on the morphological characterization according to its colonial and microscopic properties comparing with fungal species described by Fassatiova (1986). The strain was maintained on malt extract agar medium at $4^{\circ} \mathrm{C}$.

\section{Fermentative media}

In the screening step, three carbon sources were used as substrate for inulinase production. Jerusalem artichoke flour and onion flour were obtained by lyophilizing, using the lyophilizator Alpha1-4, Martin Christ. The buckwheat flour and soy flour were purchased from local market. The yeast extract was purchased from Sigma Aldrich.

Based on Plackett-Burman design by varying the composition of chosen independent variables, 16 variants of fermentative media were obtained (Tab. 1). The media composition is expressed as $\mathrm{g} / 100 \mathrm{~mL}$ of medium. The $\mathrm{pH}$ was corrected at 5.5 values. The media were prepared in Erlenmeyer flasks and sterilized at $121^{\circ} \mathrm{C}, 15$ minutes.

\section{Inoculum preparation}

Vegetative inoculum was prepared by transferring one loop of mycelium growth on the slant agar medium in 200 $\mathrm{mL}$ of sterile malt extract broth, $\mathrm{pH}=5.5$, and incubation for 3 days at $25^{\circ} \mathrm{C}$ on the orbital shaker at $100 \mathrm{rpm}$.

\section{Submerged fermentation}

In the screening process, each sample was inoculated with $10 \%$ of vegetative inoculum, and then incubated for 2 days on the orbital shaker, at different temperatures and agitation rates. The temperature and agitation rate were considered factors for the Plackett-Burman design and their variation in experimental conditions was according to the data presented in Tab. 1.

\section{Enzymes assay}

At the end of fermentation process, samples were centrifuged at $9000 \mathrm{rpm}$, at $4^{\circ} \mathrm{C}$ for 15 minutes (using the cooling centrifuge Hettich) and the supernatant was used as crude enzymes (inulinase and invertase).

Inulinase and invertase activities were determined by measuring the amount of reducing sugars released from substrates (inulin and saccharose) using 3,5-dinitrosalicylic acid (DNS) method. Calibration curves were obtained with $0.1 \%(\mathrm{w} / \mathrm{v})$ fructose solution and an equimolar mixture of $0.1 \%(\mathrm{w} / \mathrm{v})$ glucose and fructose.

The inulinase activity was determined by measuring the fructose released from the hydrolysis of $0.2 \%(\mathrm{w} / \mathrm{v})$ inulin solution. Briefly, $1 \mathrm{~mL}$ of $0.2 \%(\mathrm{w} / \mathrm{v})$ inulin solution was mixed with $0.7 \mathrm{~mL}$ of $0.1 \mathrm{M}$ acetate buffer $(\mathrm{pH}=5.5)$ and $0.3 \mathrm{~mL}$ of crude enzyme. The mixture was incubated for 20 minutes, at $30^{\circ} \mathrm{C}$ and the reaction was stopped by boiling the samples. After cooling, $2 \mathrm{~mL}$ of DNS reagent were added and the samples were further analyzed according to DNS method. Control samples were analyzed using the same procedure without incubation period. One unit of inulinase activity (UI) was defined as the amount of reducing sugars released by one $\mathrm{mL}$ of crude enzyme per hour under the assay conditions used in this study.

The invertase activity was determined similar with inulinase activity; the difference was in the substrate used, $0.2 \%(\mathrm{w} / \mathrm{v})$ sucrose solution and the incubation temperature, which was $60^{\circ} \mathrm{C}$ for invertase assay. One unit of invertase activity (UI) was defined as the amount of reducing sugars released by one $\mathrm{mL}$ of crude enzyme per hour under the assay conditions used in this study. All the samples were made in duplicate.

\section{Statistical analysis}

The statistically planned experiment is used to identify the significant variables that influence the fructofuranosidases production. The Plackett-Burman design assumes that are no interactions between the different studied variables in the range taken into consideration. So it uses the linear approach for screening many variables with as few experiments as possible. The main effects, sum of squares (SS), F-ratio, p-values, t-values and confidence intervals are calculated by the software and together with normal probability plot establish the influence of the studied variables on enzyme production. The independent variables and their levels are presented in Tab. 1 . The experimental design is showed in Tab. 2.

Eight parameters were investigated and two response variables were selected: inulinase activity and invertase activity. All the samples analyzed presented inulinase activity, according to the $\mathrm{S} / \mathrm{I}$ ratio. The Unscrambler X software (from CAMO Software) was used for the experiment design and data analysis.

The linear model used by software for the tested experimental conditions can be described with the equation (1).

Enzyme activity $=\mathrm{b}_{0}+\mathrm{b}_{1} \mathrm{~A}+\mathrm{b}_{2} \mathrm{~B}+\mathrm{b}_{3} \mathrm{C}+\mathrm{b}_{4} \mathrm{D}+\mathrm{b}_{5} \mathrm{E}+\mathrm{b}_{6} \mathrm{~F}$

$$
+\mathrm{b}_{7} \mathrm{G}+\mathrm{b}_{8} \mathrm{H}^{2} \quad \text { eq. (1) }
$$

Where A-H are the independent variables studied and $\mathrm{b}_{0}-\mathrm{b}_{8}$ are the regression coefficients.

Tab. 1. The independent variables and their levels for the Plackett-Burman design

\begin{tabular}{lcccc}
\hline \multirow{2}{*}{ Independent variables } & \multirow{2}{*}{ Code } & \multicolumn{3}{c}{ Levels of variations } \\
\cline { 3 - 5 } & & -1 & 0 & +1 \\
\hline Onion flour, \% & $\mathrm{A}$ & 0 & 3 & 6 \\
\hline Jerusalem artichoke flour, \% & $\mathrm{B}$ & 0 & 3 & 6 \\
\hline Yeast extract content, \% & $\mathrm{C}$ & 0 & 1 & 2 \\
\hline Soy flour content, \% & $\mathrm{D}$ & 0 & 1 & 2 \\
$\mathrm{~K}_{2} \mathrm{HPO}_{4} \%$ & $\mathrm{E}$ & 0 & 0.5 & 1 \\
Temperature, $^{\circ} \mathrm{C}$ & $\mathrm{F}$ & 20 & 30 & 40 \\
\hline Agitation rate, rpm & $\mathrm{G}$ & 0 & 100 & 200 \\
\hline Buckwheat flour content, $\%$ & $\mathrm{H}$ & 0 & 3 & 6 \\
\hline
\end{tabular}




\section{Results and discussion}

Various substrates can be used for inulinase and invertase production, but carbohydrate rich feedstocks are more advantageous than pure substrates. In this study, three inulin rich substrates were used for fructofuranosidase production: onion, buckwheat and Jerusalem artichoke. The carbon sources were selected based on inulinase production ability, from eleven different raw materials (i.e. onion, garlic, dahlia, Jerusalem artichoke, rye, buckwheat, oat, malt, lyophilized acid whey, pure inulin and rice). The

Tab. 2. The experimental design of the biotechnological conditions (independent variables) variation on fructofuranosidases biosynthesis

\begin{tabular}{cccccccccccc}
\hline \multirow{2}{*}{ Samples } & \multicolumn{8}{c}{ Independent variable } & $\begin{array}{c}\text { Inulinase } \\
\text { activity, } \\
\text { UA }\end{array}$ & $\begin{array}{c}\text { Invertase } \\
\text { activity, } \\
\text { UA }\end{array}$ \\
\cline { 2 - 8 } & A & B & C & D & E & F & G & H & UA & UA \\
\hline & 1 & -1 & 1 & -1 & -1 & -1 & 1 & 1 & 5.5651 & 1.6855 \\
2 & 1 & 1 & -1 & 1 & -1 & -1 & -1 & 1 & 0 & 0 \\
\hline 3 & -1 & 1 & 1 & -1 & 1 & -1 & -1 & -1 & 2.6325 & 1.8822 \\
4 & 1 & -1 & 1 & 1 & -1 & 1 & -1 & -1 & 0 & 0 \\
\hline 5 & 1 & 1 & -1 & 1 & 1 & -1 & 1 & -1 & 2.4825 & 1.7511 \\
6 & 1 & 1 & 1 & -1 & 1 & 1 & -1 & 1 & 1.7323 & 2.0601 \\
\hline 7 & -1 & 1 & 1 & 1 & -1 & 1 & 1 & -1 & 1.0639 & 0.8053 \\
8 & -1 & -1 & 1 & 1 & 1 & -1 & 1 & 1 & 6.2198 & 4.7664 \\
\hline 9 & -1 & -1 & -1 & 1 & 1 & 1 & -1 & 1 & 0.4774 & 0.7491 \\
10 & 1 & -1 & -1 & -1 & 1 & 1 & 1 & -1 & 0.6138 & 0 \\
\hline 11 & -1 & 1 & -1 & -1 & -1 & 1 & 1 & 1 & 1.9680 & 1.1650 \\
12 & -1 & -1 & -1 & -1 & -1 & -1 & -1 & -1 & 0 & 0.9083 \\
13 & 0 & 0 & 0 & 0 & 0 & 0 & 0 & 0 & 3.5328 & 1.7605 \\
14 & 0 & 0 & 0 & 0 & 0 & 0 & 0 & 0 & 2.1006 & 1.6668 \\
\hline 15 & 0 & 0 & 0 & 0 & 0 & 0 & 0 & 0 & 1.8278 & 0.9645 \\
16 & 0 & 0 & 0 & 0 & 0 & 0 & 0 & 0 & 0.1637 & 0.7585 \\
\hline
\end{tabular}

highest inulinase activity of $1.53 \mathrm{UI}$, was obtained when Jerusalem artichoke was used as carbon source, after $48 \mathrm{~h}$ of fermentation. Also, by using buckwheat and onion flours as carbon sources fungal strain presented high inulinase activities, of 1.22 UI, after 48 hours of fermentation (data not shown). Sharma et al. (2006) obtained also, maximum of inulinase activity in the second day of culturing, when various inulin rich plant substrates were used for inulinase production.

As many microbial preparations with inulinase activity (I) possess also invertase activity $(S)$, their catalytic activity is described in terms of $S / \mathrm{I}$ ratio. Thus, if $S / \mathrm{I}$ ratio is lower than 50, the enzyme preparation has preponderant inulinase activity. In contrast, if S/I ratio is higher than 50, the invertase activity is preponderant (Mazutti et al., 2006; Sharma et al., 2006).

In this study, by varying the fermentative conditions, the $S / I$ ratio varied between 0 and 7.3. The results confirm the ability of selected fungal strain to produce high level of extracellular inulinase comparing with the production of invertase. Similar results were observed also in literature (Kango, 2008; Sharma et al., 2006). It is important to control the level of production of the two fructofuranosidases ratio by changing the biotechnological conditions of cultivation.

The first step for the medium composition and process parameters optimization is screening for the most important variables that could affect enzymes production. Plackett-Burman design was used to select among the most important variables for the production of fructofuranosidases. The experimental matrix used for Plackett-Burman design is presented in Tab. 2.

As it can be seen from Tab. 3, the linear model fits well for variable screening as the $p$-value is lower than 0.05 . For both inulinase and invertase activities the summary shows that the model isglobally significant, so it can be interpreted.

Tab. 3. ANOVA analysis for inulinase and invertase biosynthesis potential in experimental analyzed conditions

\begin{tabular}{|c|c|c|c|c|c|c|}
\hline \multirow{2}{*}{ Statisical parameters } & \multicolumn{3}{|c|}{ Inulinase biosynthesis } & \multicolumn{3}{|c|}{ Invertase biosynthesis } \\
\hline & SS & F-ratio & $\mathrm{p}$-value & SS & F-ratio & p-value \\
\hline \multicolumn{7}{|l|}{ Summary } \\
\hline Model & 52.4248 & 6.6398 & 0.0109 & 19.1874 & 4.6766 & 0.0282 \\
\hline Error & 6.9086 & & & 3.5900 & & \\
\hline Corr. total & 59.3334 & & & 22.7774 & & \\
\hline \multicolumn{7}{|l|}{ Independent Variables } \\
\hline A Onion flour & 0.6661 & 0.6750 & 0.4384 & 2.7675 & 5.3962 & 0.0532 \\
\hline B Jerusalem artichoke flour & 0.4842 & 0.4906 & 0.5063 & 0.0133 & 0.0258 & 0.8768 \\
\hline C Yeast extract & 11.0106 & 11.1563 & 0.0124 & 3.7105 & 7.2350 & 0.0311 \\
\hline D Soy flour & 0.8151 & 0.8258 & 0.3937 & 0.0224 & 0.0437 & 0.8403 \\
\hline E $\mathrm{K}_{2} \mathrm{HPO}_{4}$ & 3.8872 & 3.9386 & 0.0876 & 4.7305 & 9.2237 & 0.0189 \\
\hline F Temperature & 10.4942 & 10.6331 & 0.0138 & 3.2664 & 6.3691 & 0.0396 \\
\hline G Agitation & 17.1351 & 17.3618 & 0.0042 & 2.4872 & 4.8496 & 0.0635 \\
\hline H Buckwheat flour & 7.9323 & 8.0373 & 0.0252 & 2.1897 & 4.2696 & 0.0776 \\
\hline Linear & 52.4248 & 6.6398 & 0.0109 & 19.1874 & 4.6766 & 0.0282 \\
\hline Lack of fit & 1.1826 & 0.1549 & 0.9483 & 2.8383 & 2.8317 & 0.2095 \\
\hline
\end{tabular}


274

Tab. 4. B-coefficients for extracellular fructofuranosidases biosynthesis yield

\begin{tabular}{cccc}
\hline \multicolumn{2}{c}{$\begin{array}{c}\text { Inulinase activity } \\
\text { B-coefficients }\end{array}$} & \multicolumn{2}{c}{$\begin{array}{c}\text { Invertase activity } \\
\text { B-coefficients }\end{array}$} \\
\hline $\mathrm{b}_{0}$ & 1.8195 & $\mathrm{~b}_{0}$ & 1.2463 \\
$\mathrm{~b}_{3}$ & 0.9579 & $\mathrm{~b}_{3}$ & 0.5561 \\
$\mathrm{~b}_{6}$ & -0.9352 & $\mathrm{~b}_{5}$ & 0.6279 \\
$\mathrm{~b}_{7}$ & 1.1950 & $\mathrm{~b}_{6}$ & -0.5217 \\
$\mathrm{~b}_{8}$ & 0.8130 & & \\
\hline
\end{tabular}

R-squared and adjusted R-squared for inulinase production are $88.36 \%$ and $75.05 \%$ respectively, good values having in mind that the Plackett-Burman model estimates only the linear variation and doesn't estimate the curvature. Also, for invertase activity, R-squared is $84.24 \%$.

Studying the parameters from the ANOVA statistical analysis, it can be easily observed that agitation rate has the greatest influence on inulinase production. The agitation rate helps for inulinase excretion from the cell, also observed by Chen et al. (2011) which optimized the extraction parameters of inulinase obtained by solid state fermentation of Aspergillus ficuum. The yeast extract and buckwheat flour have positive effects and temperature has a negative effect for inulinase production. The inulinase activity is higher at low temperature (Tab. 3).

Yu et al. (2009) obtained maximum inulinase activity at $5 \mathrm{~g} / \mathrm{L}$ yeast extract and low temperature $\left(28^{\circ} \mathrm{C}\right)$ by a mutant of the marine yeast Pichia guilliermondii. Kango (2008) studied the effect of nitrogen source (peptone, beef extract, yeast extract, casein, CSL) on inulinase production by Aspergillus niger and obtained maximum inulinase activity when yeast extract was used. Also, Gong et al. (2007) studied the effect of yeast extract, polypeptone, wheat bran, urea, ammonium sulphate and ammonium chloride on inulinase production and observed the best inulinase activity when yeast extract was used as nitrogen source.

The invertase production is positively influenced by the yeast extract content and $\mathrm{K}_{2} \mathrm{HPO}_{4}$ concentration in the medium and negatively influenced by the temperature of cultivation, as observed in ANOVA statistical analysis (Tab. 3). The invertase biosynthesis is higher at low temperatures. Also, Uma et al. (2010) observed that the invertase obtained from Aspergillus flavus using fruit peel waste as substrate was active when reaction mixture was kept at $30^{\circ} \mathrm{C}$, but at higher temperature the enzyme activity was not significant due probably to the thermal denaturation of the enzyme active site.

Yeast extract was found to have positive influence on invertase biosynthesis (Tab. 3). The effect of different nitrogen sources on invertase production was tested also by Uma et al. (2010) using Aspergillus flavus, and the enzyme production was more pronounced also by the use of yeast extract. Yeast extract has a positive influence on invertase production by Saccharomyces cerevisiae strain also, as reported by Venkateshwar et al. (2009). For Streptomyces spp. a significant invertase production was observed when $\mathrm{NaNO}_{3}$ in combination with yeast extract was used as nitrogen source. These results suggest a preference of the microbial species for a specific nitrogen source for optimal production of invertase (Kaur and Sharma, 2005).

Mineral nutrients affect the enzyme production and $\mathrm{K}_{2} \mathrm{HPO}_{4}$ has a positive effect on invertase biosynthesis. Similar results were reported also by Venkateshwar $e t$ al. (2010).

In Tab. 4, B-coefficients are presented for both inulinase and invertase yield for linear model as described by Plackett-Burman design.

As only yeast extract, temperature, agitation and buckwheat flour are important for inulinase production, only these terms of eq. (1) will be calculated. For invertase production, yeast extract, $\mathrm{K}_{2} \mathrm{HPO}_{4}$ and temperature are most important parameters.

\section{Conclusions}

Many agro-industrial residues can be used as ingredients in fermentative media for fructofuranosidases production. Also, many microbial strains are able to produce these enzymes.

A newly isolated Rhizoctonia spp. strain, which proved to have a great capacity to produce inulinase, was used for fructofuranosidases production. In this study three carbon sources, two nitrogen sources, a salt and two physical parameters (temperature and agitation rate) were studied and selected as important variables in a Plackett-Burman model that can influence the extracellular fructofuranosidases production and ratio between the two enzymes, inulinase and invertase biosynthesis yields. Agitation had the greatest positive influence on inulinase production, followed by concentration of buckwheat flour and yeast extract concentrations.

Yeast extract content and $\mathrm{K}_{2} \mathrm{HPO}_{4}$ concentration had a positive effect on invertase production. Temperature has a negative effect for both invertase and inulinase production. High levels of temperatures conducted to low fructofuranosidases yields.

In the future the correlative effect of this screened variable will be tested in order to optimize the biotechnological conditions to increase the fructofuranosidases biosynthesis yield and to control the ratio between the enzymes of the enzymatic complex. The statistical approach enables rapid identification and optimization of principal process parameters for fructofuranosidases production by the newly isolated Rhyzoctonia spp. strain.

\section{Acknowledgements}

This work was supported by CNCSIS-UEFISCSU, project number PN II-RU 503/2010. 


\section{References}

Bender JP, Mazutti MA, Oliveira D, Luccio M, Treichel H (2006). Inulinase production by Kluyveromyces marxianus NRRL Y-7571 using solid state fermentation. Appl Biochem Biotech 129-132:951-958.

Bonciu C, Struta V, Bahrim G (2010) Isolation and screening of new mould strains able for inulinase biosynthesis and inulin from Jerusalem artichoke hydrolysis. Innov Rom Food Biotech 7:77-81.

Chen HQ, Chen XM, Chen TX, Xu XM, Jin ZY (2011) Extraction optimization of inulinase obtained by solid-state fermentation of Aspergillus ficuum JNSP5-06. Carbohydr Polym 85:446-451.

Chi Z, Chi Z, Zhang T, Liu G (2009) Inulinase-expressing microorganisms and applications of inulinases. Appl Microb Biotech 82:211-220.

Chi ZM, Zhang T, Cao TS, Liu XY, Cui W, Zhao CH (2011) Biotechnological potential of inulin for bioprocesses. Biores Technol 102:4295-4303.

Fassatiova, O (1986) Progress in industrial microbiology. Moulds and filamentous fungi in technical microbiology. Elsevier, New York.

Gao L, Chi Z, Shend J, Wang L, Li J, Gong F (2007) Inulinaseproducing marine yeasts: evaluation of their diversity and inulin hydrolysis by their crude enzymes. Microb Ecol 54:722-729.

Gern RMM, Furlan SA, Ninow JL, Jonas R (2001) Screening for microorganisms that produce only endo-inulinase. Appl Microb Biotech 55:632-635.

Gong F, Sheng J, Chi Z, Li J (2007) Inulinase production by a marine yeast Pichia guilliermondii and inulin hydrolysis by the crude inulinase. J Ind Microbiol Biotechnol 34:179-185.

Kalil S, Suzan R, Maugeri F, Rodrigues MI (2001) Optimization of inulinase production by Kluyveromyces marxianus using factorial design. Appl Biochem Biotech 94:257-264.

Kang SI, Chang YJ, Oh SJ, Kim SI (1998) Purification and properties of an endo-inulinase from an Arthrobacter sp. Biotechnol Lett 20(10):983-986.

Kango N (2008) Production of inulinase using tap roots of dandelion (Taraxacum officinale) by Aspergillus niger. J Food Eng 85:473-478.

Kaur N, Sharma AD (2005) Production, optimization and characterization of extracellular invertase by an actinomycete strain. J Sci Ind Research 64: 515-519.

Kim DH, Choi YJ, Song SK, Yun JW (1997) Production of inulo-oligosaccharides using endo-inulinase from Pseudomonas sp. Biotechnol Lett 19(4):369-371.

Kumar GP, Kunamneni A, Prabhakar T, Ellaiah P (2005) Optimization of process parameters for the production of inulinase from a newly isolated Aspergillus niger AUP19. World J Microb Biotech 21:1359-1361.
Kushi RT, Monti R, Contiero J (2000) Production, purification and characterization of an extracellular inulinase from Kluyveromyces marxianus var. bulgaricus. J Ind Microb Biotech 25:63-69.

Mazutti M, Bender JP, Treichel H, Luccio M (2006) Optimization of inulinase production by solid-state fermentation using sugarcane bagasse as substrate. http:// www.aseanbiotechnology.info/Abstract/21018959.pdf.

Mazutti M, Ceni G, Luccio M, Treichel H (2007) Production of inulinase by solid-state fermentation: effect of process parameters on production and preliminary characterization of enzyme preparations. Bioprocess Biosyst Eng 30:297304.

Pessoa A, Vitolo M (1998) Downstream processing of inulinase, comparison of different techniques. Appl Biochem Biotech 70-72:505-511.

Sharma AD, Kainth S, Gill PK (2006) Inulinase production using garlic (Allium sativum) powder as a potential substrate in Streptomyces spp. J Food Eng 77:486-491.

Sheng J, Chi Z, Gong F, Li J (2008) Purification and characterization of extracellular inulinase from a marine yeast Cryptococcus aureus $\mathrm{G} 7 \mathrm{a}$ and inulin hydrolysis by the purified enzyme. Appl Biochem Biotechnol 144:111-121.

Sing RS, Dhaliwal R, Puri M (2006) Production of inulinase from Kluyveromyces marxianus YS-1 using root extract of Asparagus racemosus. Process Biochem 41:1703-1707.

Treichel H, Mazutti MA, Filho FM, Rodrigues MI (2009) Technical viability of the production, partial purification and characterization of inulinase using pretreated agroindustrial residues. Bioprocess Biosyst Eng 32:425-433.

Uma C, Gomathi D, Muthulakshmi C, Gopalakrishnan VK (2010) Production, purification and characterization of invertase by Aspergillus flavus using fruit peel waste as substrate. Advan Biol Res 4(1):31-36.

Venkateshwar M, Chaitanya K, Altaf MD, Hameeda B, Reddy M (2009) Evaluation of nitrogenous media components by Plackett-Burman statistical design for [beta]-Dfructofuranosidase production by Saccharomyces sp. strain GVT263. Canadian J Microb 55(4):405-409.

Venkateshwar M, Chaitanya K, Altaf MD, Mahammad EJ, Hameeda B, Reddy GM (2010) Influence of micronutrients on yeast grow and $\beta$-D-fructofuranosidase production. Indian J Microb 50: 325-331.

Yu X, Guo N, Chi Z, Gong F, Sheng J, Chi Z (2009) Inulinase overproduction by a mutant of the marine yeast Pichia guilliermondii using surface response methodology and inulin hydrolysis. Biochemical Eng J 43:266-271. 